\title{
Hypopituitarism following traumatic brain injury: determining factors for diagnosis
}

\section{Eva Fernandez-Rodriguez ${ }^{1}$, Ignacio Bernabeu ${ }^{1}$, Ana Isabel Castro ${ }^{1}$, Fahrettin Kelestimur ${ }^{2}$ and Felipe F. Casanueva ${ }^{1,3 *}$}

\author{
Endocrinology Division, Complejo Hospitalario Universitario de Santiago de Compostela, SERGAS, Departamento de Medicina, Universidad de Santiago de \\ Compostela, Santiago de Compostela, Spain \\ 2 Department of Endocrinology, Erciyes University Medical School, Kayseri, Turkey \\ ${ }^{3}$ Centro de Investigación Biomédica en Red de Fisiopatología Obesidad y Nutrición, Instituto Salud Carlos III, Santiago de Compostela, Spain
}

\section{Edited by:}

Sally Radovick, Johns Hopkins

University, USA

Reviewed by:

Thierry C. Brue, Université de la Méditerranée/Assistance Publique Hôpitaux de Marseille, France Christopher Joseph Romero, Johns Hopkins University School of

Medicine, USA

\section{*Correspondence:}

Felipe F. Casanueva, Endocrinology

Division, Hospital Clinico

Universitario, Travesía da Choupana, s/n 15706 Santiago de Compostela, La Coruña, Spain.

e-mail:endocrine@usc.es
Neuroendocrine dysfunction, long recognized as a consequence of traumatic brain injury (TBI), is a major cause of disability that includes physical and psychological involvement with long-term cognitive, behavioral, and social changes. There is no standard procedure regarding at what time after trauma the diagnosis should be made. Also there is uncertainty on defining the best methods for diagnosis and testing and what types of patients should be selected for screening. Common criteria for evaluating these patients are required on account of the high prevalence of TBI worldwide and the potential new cases of hypopituitarism. The aim of this review is to clarify, based on the evidence, when endocrine assessment should be performed after TBI and which patients should be evaluated. Additional studies are still needed to know the impact of post-traumatic hypopituitarism and to assess the impact of hormone replacement in the prognosis.

Keywords: hypopituitarism, traumatic brain injury, growth hormone deficiency, hypogonadism
Traumatic brain injury (TBI) is a significant public health problem worldwide, with an overall incidence in Western countries of 200-235 cases per 100,000 individuals annually (Tagliaferri et al., 2006). Approximately $20-40 \%$ of TBI episodes involve moderate to severe traumatic injuries (Frankowski et al., 1985), while 10\% of cases are fatal.

In young adults TBI is considered one of the main causes of death (Hodgson et al., 2000). Moreover, it is a major cause of disability that includes physical and psychological involvement with long-term cognitive, behavioral, and social changes (Salazar et al., 2000; Khan et al., 2003). Neuroendocrine dysfunction has long been recognized as a consequence of TBI (Cyran, 1914), particularly in moderate and severe cases, although the last 10 years have witnessed a better understanding of the frequency of TBImediated hypopituitarism and its clinical implications, with the publication of an increasing number of studies (Benvega et al., 2000; Kelly et al., 2000; Lieberman et al., 2001; Agha et al., 2004; Bondanelli et al., 2004; Popovic et al., 2004; Aimaretti et al., 2005; Leal-Cerro et al., 2005; Herrmann et al., 2006; Schneider et al., 2006; Tanriverdi et al., 2006).

This review is focused in adult patients, but there is also recent data about TBI-induced hypopituitarism in children and adolescents (Khadr et al., 2010; Moon et al., 2010; Norwood et al., 2010).

\section{EPIDEMIOLOGY OF HYPOPITUITARISM}

Despite the high prevalence of TBI in the general population, brain injury-related hypopituitarism remains largely under-diagnosed (Ghigo et al., 2005; Gasco et al., 2010). Brain damage often presents with signs and symptoms that can easily mask the typical symptoms of hypopituitarism (Hellawell and Pentland, 2001), and physicians who care for such patients have little awareness about the possibility of pituitary deficiencies and their impact on the prognosis, resulting in misdiagnosed cases as an endocrine assessment is not usually considered.

To date, the prevalence of reported hypopituitarism following TBI varies widely among published studies (Kelly et al., 2000; Lieberman et al., 2001; Popovic et al., 2004; Leal-Cerro et al., 2005; Tanriverdi et al., 2006). Considering all degrees of hypopituitarism, from isolated pituitary deficiencies to multiple or even total hypopituitarism, the prevalence ranges from 15 to $90 \%$ (Kelly et al., 2000; Lieberman et al., 2001; Popovic et al., 2004; Leal-Cerro et al., 2005; Tanriverdi et al., 2006). A meta-analysis including 1015 patients with TBI reported a pooled prevalence of hypopituitarism of $27.5 \%$. The prevalence of anterior pituitary dysfunction in the studies included in this meta-analysis ranged from 15 to $68 \%$. The design and time of pituitary evaluation in these studies were also variable, ranging from 3 months to 7 years following the head trauma (Schneider et al., 2007).

\section{PATHOPHYSIOLOGY OF HYPOPITUITARISM}

The pathophysiology of hypopituitarism following TBI is not completely understood, and several factors implicated in its development have been suggested (Dusick et al., 2008).

An important mechanism involved is infarction or ischemia of the pituitary gland (Malya et al., 2008), an explanation also supported by the high prevalence of hypopituitarism in patients with 
ischemic stroke (Bondanelli et al., 2010). Vascular damage to the pituitary can also be caused by several mechanisms:

(1) Traumatic damage to the long hypophyseal portal veins and subsequent venous infarction are thought to be the main underlying vascular mechanisms (Daniel et al., 1959; Kornblum and Fisher, 1969).

(2) Direct traumatic injury to the pituitary gland as demonstrated by the high prevalence of necrosis or hemorrhage into the pituitary gland shown in postmortem studies (Crompton, 1971; Salehi et al., 2007).

(3) Multiple secondary insults from hypotension, hypoxia, anemia, and brain swelling, which could also lead to an ischemic pituitary gland (Wachter et al., 2009).

(4) Another mechanism described as responsible for hypopituitarism due to vascular damage is transection of the pituitary stalk, which potentially causes hypopituitarism because of infarction of the pituitary tissue (Daniel et al., 1959; Malya et al., 2008).

However, recent research has indicated a possible interaction between autoimmunity and the development of hypopituitarism following TBI. It has been demonstrated that antipituitary antibodies are present in patients with TBI-induced pituitary dysfunction and persist even 3 years after diagnosis (Tanriverdi et al., 2008a, 2010a).

\section{WHICH ENDOCRINE DEFICITS ARE THE MOST FREOUENT?}

The degree of hypopituitarism, considered as the number of axes involved, and the prevalence of each pituitary deficiency differ in the various studies published. Some authors have identified central hypogonadism as the most frequent pituitary deficiency after TBI (Benvega et al., 2000; Tanriverdi et al., 2006; Wachter et al., 2009), although most have reported the GH deficiency (GHD) as the most prevalent (Bondanelli et al., 2004; Popovic et al., 2004; Aimaretti et al., 2005).

Taking into consideration all data published to date, GHD is the most common hormone deficiency in both severe and moderate TBI. However, its prevalence varied from 2 to $66 \%$, with $39 \%$ of cases of severe GHD. Prevalence of the other pituitary deficiencies was also variable among the studies and ranged from 0 to $60 \%$ for secondary adrenal insufficiency, 0 to $29 \%$ for secondary hypothyroidism, 0 to $29 \%$ for central hypogonadism, and 0 to $48 \%$ for abnormal hyperprolactinemia (Benvega et al., 2000; Kelly et al., 2000; Lieberman et al., 2001; Agha et al., 2004; Bondanelli et al., 2004; Popovic et al., 2004; Aimaretti et al., 2005; Leal-Cerro et al., 2005; Herrmann et al., 2006; Schneider et al., 2006; Tanriverdi et al., 2006; Kokshoorn et al., 2010). All cases of abnormal hyperprolactinemia were mild elevations of prolactin and had no clinical significance (Kokshoorn et al., 2010).

This variability could be explained by several factors, including a different time interval between TBI and the assessment of pituitary function (from $24 \mathrm{~h}$ to 23 years), the type and severity of brain injury, and the different methods used to evaluate pituitary function reserve, such as endocrine tests, assays, and criteria for the diagnosis of hypopituitarism (Gasco et al., 2010; Kokshoorn et al., 2010).
The study design might also influence the prevalence of hypopituitarism. Only a few studies have been designed to evaluate the incidence of hypopituitarism following TBI with specific criteria and evaluation at a particular time (Aimaretti et al., 2004, 2005; Tanriverdi et al., 2006, 2008b) and most of the studies published are retrospective or cross-sectional (Kelly et al., 2000; Lieberman et al., 2001; Agha et al., 2004; Bondanelli et al., 2004; Popovic et al., 2004; Leal-Cerro et al., 2005; Herrmann et al., 2006).

\section{WHEN SHOULD PATIENTS BE SCREENED AFTER TBI?}

The time interval between TBI and pituitary hormone assessment is one of the major factors responsible for variations in the prevalence of hypopituitarism.

The presence of pituitary dysfunction in the early acute phases (first $24 \mathrm{~h}$ ) or acute phases (up to 2-3 weeks) following TBI was not related to hypopituitarism after 12 months (Tanriverdi et al., 2006,2008 b), as pituitary function was recovered in many patients (Tanriverdi et al., 2008b). Indeed, pituitary deficiencies were found in $56 \%$ of patients when endocrine evaluation was performed 3 months after TBI. However, when it was performed 12 months after TBI, pituitary deficiencies were only detected in $36 \%$ of cases. GHD was detected in 9 and $10 \%$, at 3 and 12 months after TBI, respectively. Hypogonadism was detected in 32 and $20 \%$, ACTH deficiency in 19 and 9\%, and TSH deficiency in 8 and 3\%, respectively (Schneider et al., 2006).

Prospective studies have shown the dynamic property of hypopituitarism in isolated and multiple pituitary deficiencies as well as in the worsening or recovery of pituitary function (Aimaretti et al., 2005; Tanriverdi et al., 2006, 2008b). Pituitary recovery 12 years after TBI was also reported (Ruggeri et al., 2010), possibly due to pituitary revascularization and cellular pituicyte repopulation (Benvega et al., 2000).

In the early post-traumatic period there are often hormonal changes that mimic pituitary dysfunction (Klose et al., 2007a). This is included in the physiological response to acute and critical illness, which comprises hormonal changes similar to GHD, central hypogonadism, and hypothyroidism (Van den et al., 1998). Acute illness or drugs frequently used in these clinical conditions could alter the metabolism of the protein binding hormones, resulting in false deficiencies (Agha et al., 2005a).

On the other hand, stress hormones such as cortisol, prolactin, and vasopressin are increased (Hamrahian et al., 2004; Jochberger et al., 2006). Consequently, as cortisol should be increased in the acute phase after TBI, low or low-normal baseline free cortisol could still be proposed as a potential early marker for the development of chronic ACTH deficiency in head trauma patients (Klose et al., 2007a).

This overestimation of hypopituitarism in the acute phase following TBI makes it reasonable to propose the evaluation of pituitary function at least 1 year after the head trauma and not at an earlier time point, particularly for hormones that do not necessarily need to be replaced urgently, such as the gonadal and somatotropic axes (Lorenzo et al., 2005).

\section{WHICH PATIENTS SHOULD BE SELECTED FOR SCREENING?}

Severity of head trauma has been proposed as a predictor of occurrence of hypopituitarism and is evaluated by the Glasgow Coma 
Scale (GCS) Score (Teasdale and Jennett, 1974) according to the consciousness level and ocular and motor movements.

We propose an algorithm (Figure 1) to know who are the patients that should be screened for pituitary function, based on evidence.

Many studies (Kelly et al., 2000; Lieberman et al., 2001; Schneider et al., 2006; Tanriverdi et al., 2006) showed that pituitary deficiencies were more frequent in cases of moderate and severe head trauma (GCS $<13$ ), although patients with severe disability, as vegetative states, will not benefit from hormonal replacement and should be excluded from non-vital deficiency assessment. On the other hand, other authors did not find any association between injury severity and prevalence of hypopituitarism (Agha et al., 2004; Aimaretti et al., 2005; Leal-Cerro et al., 2005; Tanriverdi et al., 2006). In addition, low-intensity repeated trauma, which occurs in certain sports, may also result in pituitary deficiencies (Tanriverdi et al., 2010b) probably related to a decrease in pituitary volume (Tanriverdi et al., 2008c).

Mild TBI, defined as a score between 13 and 15 in the GCS, is associated with more frequent isolated pituitary deficiencies with a higher proportion of axes recovered after 1 year of follow-up (Tanriverdi et al., 2006). Conversely, studies published to date collectively indicate that at 6-2 months post-injury, $25-40 \%$ of moderate, and severe TBI patients will develop chronic hypopituitarism with the somatotropic and gonadotropic axes being most commonly affected and with a high proportion of persistent deficiencies (Schneider et al., 2006; Tanriverdi et al., 2006, 2008b). Indeed, the pooled prevalence of hypopituitarism in cases of severe, moderate and mild TBI reported by Schneider et al. (2007) was $35.3,10.9$, and $16.8 \%$, respectively.
There is no cost/benefit indication for global screening of all cases of mild TBI (Ghigo et al., 2005). However, some situations, such as the presence of anatomic abnormalities on initial CT (diffuse axonal injury or skull fractures; Schneider et al., 2008), diffuse brain swelling, hypoxia, hypotension (Kelly et al., 2000), duration of coma (Benvega et al., 2000), increased intracranial pressure, longer intubation and hospitalization, and advanced age have been associated with a worse prognosis and higher incidence of hypopituitarism (Becker et al., 1977; Bullock et al., 1996; Hellawell and Pentland, 2001).

\section{WHICH ARE THE MOST APPROPRIATE TESTS FOR ENDOCRINE ASSESSMENT?}

Brain injury-related hypopituitarism is under-diagnosed (Schneider et al., 2007; Gasco et al., 2010), but as the health resources of any population are limited, screening every patient who undergoes any head trauma for hypopituitarism should not be recommended. Accordingly, the most important aspect concerning the diagnosis of TBI-associated hypopituitarism is to define the conditions related to an increased risk of hypopituitarism, the time interval from TBI when it is best to evaluate and the endocrine test that should be performed in such cases.

Endocrine tests and criteria for diagnosis vary among the studies published. In the case of the GH-IGF-1 axis all patients were diagnosed with a dynamic test in addition to basal GH and IGF-1 values. However, the dynamic tests used also differ among the studies and include the insulin tolerance test (Kelly et al., 2000; Klose et al., 2007a), the glucagon stimulation test (Agha et al., 2004; Bushnik et al., 2004; Leal-Cerro et al., 2005), the GHRH-arginine test (Bondanelli et al., 2004; Aimaretti et al., 2005; Herrmann et al.,

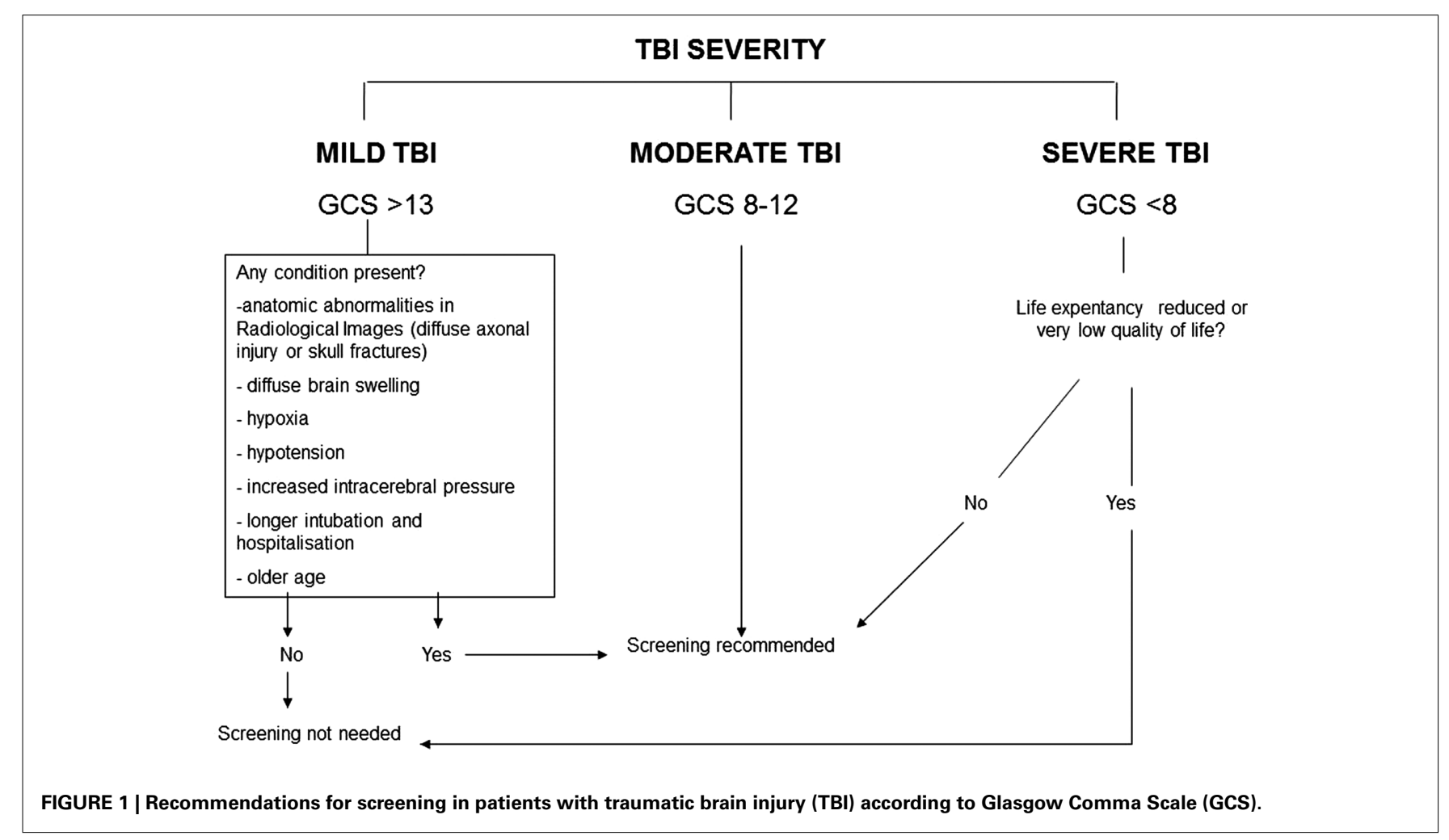


2006), and the GHRH-GHRP6 test (Popovic et al., 2004; Tanriverdi et al., 2006). The vagaries of GH provocation test are well known (Ho, 2007). The optimal diagnostic is the one that identifies those patients that will benefit from treatment with $\mathrm{GH}$ and excludes those that will not (Blair, 2010). The GHRH-GHRP6 test is rigorous and reliable (Popovic et al., 2000) and is not affected by known factors that modify GH secretion such as obesity. It has demonstrated its utility in the diagnosis of GHD after TBI (Popovic et al., 2004; Tanriverdi et al., 2006) even in a single assay after a 30-min test (Castro et al., 2007), which is essential from a practical point of view. A GH peak of under $10 \mu \mathrm{g} / \mathrm{l}$ will confirm the diagnosis and above $20 \mu \mathrm{g} / \mathrm{l}$ will exclude GHD. In cases between 10 and $20 \mu \mathrm{g} / \mathrm{l}$ another test is needed.

In the case of the adrenal axis, adrenal insufficiency can be diagnosed with a basal level of cortisol when it is extremely low (under $50 \mathrm{nmol} / \mathrm{l}, 1.8 \mu \mathrm{g} / \mathrm{dl}$ ). For the other cases a stimulation test is needed, and the ACTH stimulation (Lieberman et al., 2001; Tanriverdi et al., 2006) and insulin tolerance tests (Kelly et al., 2000; Agha et al., 2005b; Leal-Cerro et al., 2005; Herrmann et al., 2006) are considered the most appropriate for diagnosis with a cut-off cortisol level of $550 \mathrm{nmol} / \mathrm{l}(20 \mu \mathrm{g} / \mathrm{dl})$. In the studies previously mentioned, ACTH stimulation test was either performed with $250 \mu \mathrm{g}$ of cosyntropin (Lieberman et al., 2001) and $1 \mu \mathrm{g}$ of tetracosactrin (Tanriverdi et al., 2006).

For the thyroid, gonadal, and prolactin axes basal levels are enough for a diagnosis to be made (Aimaretti et al., 2005; Herrmann et al., 2006; Tanriverdi et al., 2008b). Low levels of free T4 with normal or low TSH allow diagnosis of central hypothyroidism to be made, and low levels of testosterone or estrogens with normal or low FSH and LH are diagnostic of central hypogonadism (Popovic et al., 2004; Herrmann et al., 2006; Klose and FeldtRasmussen, 2008). Abnormal prolactin is also diagnosed when basal prolactin levels are not within the normal range (Lieberman et al., 2001; Popovic et al., 2004; Herrmann et al., 2006; Klose and Feldt-Rasmussen, 2008).

\section{OUTCOME}

Pituitary function affects TBI patient outcome. Hypopituitarism is thought to contribute to TBI-associated morbidity (Klose and Feldt-Rasmussen, 2008) and to functional and cognitive final outcome (Bondanelli et al., 2007). In addition, GHD has the

\section{REFERENCES}

Agha, A., Ryan, J., Sherlock, M., and Thompson, C. J. (2005a). Spontaneous recovery from posttraumatic hypopituitarism. Am. J. Phys. Med. Rehabil. 84, 381-385.

Agha, A., Phillips, J., O’Kelly, P., Tormey, W., and Thompson, C. J. (2005b). The natural history of posttraumatic hypopituitarism: implications for assessment and treatment. Am. J. Med. 118, 1416.

Agha, A., Rogers, B., Sherlock, M., O’Kelly, P., Tormey, W., Phillips, J., and Thompson, C. J. (2004). Anterior pituitary dysfunction in survivors of traumatic brain injury.
J. Clin. Endocrinol. Metab. 89, 4929-4936.

Aimaretti, G., Ambrosio, M. R., Di Somma, C., Fusco, A., Cannavò, S., Gasperi, M., Scaroni, C., De Marinis, L., Benvenga, S., degli Uberti, E. C., Lombardi, G., Mantero, F., Martino, E., Giordano, G., and Ghigo, E. (2004). Traumatic brain injury and subarachnoid haemorrhage are conditions at high risk for hypopituitarism: screening study at 3 months after the brain injury. Clin. Endocrinol. (Oxf.) 61, 320-326.

Aimaretti, G., Ambrosio, M. R., Di Somma, C., Gasperi, M., Cannavo, S., Scaroni, C., Fusco, A., Del Monte,

greatest effect on outcome (Kelly et al., 2006; Bondanelli et al., 2007). Moreover, a clear association has recently emerged between post-TBI neuroendocrine dysfunction and neurobehavioral and quality of life impairment (Klose and Feldt-Rasmussen, 2008), which have increased the interest of doctors in this clinical condition.

Specific evaluations of these patients demonstrated an association between hypopituitarism and especially GHD and depression and memory, neuropsychological and cognitive disorders (Kelly et al., 2006).

Hypopituitarism, when untreated, has also been associated with an adverse lipid profile, increased abdominal fat and body mass index, and deterioration in quality of life (Klose et al., 2007b). It may also be expected that would significantly impede recovery and rehabilitation following TBI (Blair, 2010).

The Pfizer International Metabolic Database (KIMS) reported a significant improvement in quality of life, assessed by the adult growth hormone deficiency assessment (AGHDA) score, in patients with post-traumatic hypopituitarism and GH treatment (Kreitschmann-Andermahr et al., 2008). Recent data also suggests that some of the cognitive impairments observed in patients with GHD after TBI can improve with GH replacement (High et al., 2010). Serious and life-threatening adrenal crises due to ACTH deficiency after TBI have significantly improved with glucocorticoid replacement (Agha et al., 2005b). However, long-term followup studies are still needed to evaluate outcome and the necessity and benefits of hormone replacement with growth hormone and gonadal steroids in these patients.

\section{CONCLUSION}

The incidence of hypopituitarism following TBI is around 50 patients per 100,000 individuals per year, which results in a high number of patients affected. Endocrine assessment should be performed 1 year after head injury and only in cases of moderate or severe TBI, or if mild TBI involves conditions related to a worse prognosis. However, additional studies are still needed to assess the impact of hormone replacement in the prognosis.

\section{ACKNOWLEDGMENTS}

CIBEROBN is an initiative of the Instituto de Salud Carlos III (ISCIII).

P., De Menis, E., Faustini-Fustini, M., Grimaldi, F., Logoluso, F., Razzore, P., Rovere, S., Benvenga, S., Degli Uberti, E. C., De Marinis, L., Lombardi, G., Mantero, F., Martino, E., Giordano, G., and Ghigo, E. (2005). Residual pituitary function after brain injury-induced hypopituitarism: a prospective 12-month study. J. Clin. Endocrinol. Metab. 90, 6085-6092.

Becker, D. P., Miller, J. D., Ward, J. D., Greenberg, R. P., Young, H. F., and Sakalas, R. (1977). The outcome from severe head injury with early diagnosis and intensive management. J. Neurosurg. 47, 491-502.
Benvega, S., Campenni, A., Ruggeri, R. M., and Trimarchi, F. (2000). Hypopituitarism secondary to head trauma. J. Clin. Endocrinol. Metab. 85, 1353-1361.

Blair, J. C. (2010). Prevalence, natural history and consequences of posttraumatic hypopituitarism: a case for endocrine surveillance. $\mathrm{Br} . \mathrm{J}$. Neurosurg. 24, 10-17.

Bondanelli, M., Ambrosio, M. R., Carli, A., Bergonzoni, A., Bertocchi, A., Zatelli, M. C., Ceruti, S., Valle, D., Basaglia, N., and degli Uberti, E. C. (2010). Predictors of pituitary dysfunction in patients surviving ischemic stroke. J. Clin. Endocrinol. Metab. 95, 4660-4668. 
Bondanelli, M., Ambrosio, M. R., Cavazzini, L., Bertocchi, A., Zatelli, M. C., Carli, A., Valle, D., Basaglia, N., and Uberti, E. C. (2007). Anterior pituitary function may predict functional and cognitive outcome in patients with traumatic brain injury undergoing rehabilitation. J. Neurotrauma 24, 1687-1697.

Bondanelli, M., De Marinis, L., Ambrosio, M. R., Monesi, M., Valle, D., Zatelli, M. C., Fusco, A., Bianchi, A., Farneti, M., and Degli Uberti, E. C. (2004). Occurrence of pituitary dysfunction following traumatic brain injury. J. Neurotrauma 21, 685-696.

Bullock, R., Chesnut, R. M., Clifton, G., Ghajar, J., Marion, D. W., Narayan, R. K., Newell, D. W., Pitts, L. H., Rosner, M. J., and Wilberger, J. W. (1996). Guidelines for the management of severe head injury. Brain Trauma Foundation. Eur. J. Emerg. Med. 3, 109-127.

Bushnik, T., Englander, J., and Duong, T. (2004). Medical and social issues related to posttraumatic seizures in persons with traumatic brain injury. J. Head Trauma Rehabil. 19, 296-304.

Castro, A. I., Lage, M., Peino, R., Kelestimur, F., Dieguez, C., and Casanueva, F. F. (2007). A single growth hormone determination 30 minutes after the administration of the GHRH plus GHRP-6 test is sufficient for the diagnosis of somatotrope dysfunction in patients who have suffered traumatic brain injury. J. Endocrinol. Invest. 30, 224-229.

Crompton, M. R. (1971). Hypothalamic lesions following closed head injury. Brain 94, 165-172.

Cyran, E. (1914). Hypophysenschädigung durch Schädel-Basis-Fraktur. Dtsch. Med. Wochenschr. 44, 1261.

Daniel, P. M., Prichard, M. M., and Treip, C. S. (1959). Traumatic infarction of the anterior lobe of the pituitary gland. Lancet 2, 927-931.

Dusick, J. R., Wang, C., Cohan, P., Swerdloff, R., and Kelly, D. F. (2008). Chapter 1: pathophysiology of hypopituitarism in the setting of brain injury. Pituitary. doi: 10.1007/s11102-008-0130-6. [Epub ahead of print].

Frankowski, R., Annegers, J., and Whitman, S. (1985). "Epidemiological and descriptive studies. Part 1: the descriptive epidemiology of head trauma in the United States," in Central Nervous System Trauma Status Report, eds D. Bevcker and J. Polishock (Bethesda, MD: National Institute Neurological and Communicative Disorders and Stroke, NIH), 33-42.

Gasco, V., Prodam, F., Pagano, L., Grottoli, S., Belcastro, S., Marzullo, P.,
Beccuti, G., Ghigo, E., and Aimaretti, G. (2010). Hypopituitarism following brain injury: when does it occur and how best to test? Pituitary. doi: 10.1007/s11102-010-0235-6. [Epub ahead of print].

Ghigo, E., Masel, B., Aimaretti, G., Léon-Carrión, J., Casanueva, F. F., Dominguez-Morales, M. R., Elovic, E., Perrone, K., Stalla, G., Thompson, C., and Urban, R. (2005). Consensus guidelines on screening for hypopituitarism following traumatic brain injury. On behalf of participants in the hypopituitarism following traumatic brain injury consensus workshop. Brain Inj. 19, 711-724.

Hamrahian, A. H., Oseni, T. S., and Arafah, B. M. (2004). Measurements of serum free cortisol in critically ill patients. N. Engl. J. Med. 350, 1629-1638.

Hellawell, D. J., and Pentland, B. (2001). Relatives' reports of long term problems following traumatic brain injury or subarachnoid haemorrhage. Disabil. Rehabil. 23, 300-305.

Herrmann, B. L., Rehder, J., Kahlke, S., Wiedemayer, H., Doerfler, A., Ischebeck, W., Laumer, R., Forsting, M., Stolke, D., and Mann, K. (2006). Hypopituitarism following severe traumatic brain injury. Exp. Clin. Endocrinol. Diabetes 114, 316-321.

High, W. M., Briones-Galang, M., Clark, J. A., Gilkison, C., Mossberg, K. A., Zgaljardic, D. J., Masel, B. E., and Urban, R. J. (2010). Effect of growth hormone therapy on cognition after traumatic brain injury. $J$. Neurotrauma 27, 1565-1575.

Ho, K. K. (2007). GH deficiency Consensus Workshop Participants. Consensus guidelines for the diagnosis and treatment of adults with GH deficiency II: a statement of the GH Research Society in association with the European Society for Pediatric Endocrinology, Lawson Wilkins Society, European Society of Endocrinology, Japan Endocrine Society and Endocrine Society of Australia. Eur. J. Endocrinol. 157, 695-700.

Hodgson, N. F., Stewart, T. C., and Girotti, M. J. (2000). Autopsies and death certification in deaths due to blunt trauma: what are we missing? Can. J. Surg. 43, 130-136.

Jochberger, S., Morgenthaler, N. G., Mayr, V. D., Luckner, G., Wenzel, V., Ulmer, H., Schwarz, S., Hasibeder, W. R., Friesenecker, B. E., and Dünser, M. W. (2006). Copeptin and arginine vasopressin concentrations in critically ill patients. J. Clin. Endocrinol. Metab. 91, 4381-4386.

Kelly, D. F., Gonzalo, I. T., Cohan, P., Berman, N., Swerdloff, R., and Wang, C. (2000). Hypopituitarism following traumatic brain injury and aneurysmal subarachnoid hemorrhage: a preliminary report. $J$. Neurosurg. 93, 743-752.

Kelly, D. F., McArthur, D. L., Levin, H. Swimmer, S., Dusick, J. R., Cohan, P. Wang, C., and Swerdloff, R. (2006) Neurobehavioral and quality of life changes associated with growth hormone insufficiency after complicated mild, moderate, or severe traumatic brain injury. J. Neurotrauma 23, 928-942.

Khadr, S. N., Crofton, P. M., Jones, P. A., Wardhaugh, B., Roach, J., Drake, A. J., Minns, R. A., and Kelnar, C. J. (2010). Evaluation of pituitary function after traumatic brain injury in childhood. Clin. Endocrinol. (Oxf.) 73, 637-643.

Khan, F., Baguley, I. J., and Cameron, I. D. (2003). Rehabilitation after traumatic brain injury. Med. J. Aust. 178 290-295.

Klose, M., and Feldt-Rasmussen, U. (2008). Does the type and severity of brain injury predict hypothalamopituitary dysfunction? Does post-traumatic hypopituitarism predict worse outcome? Pituitary 11, 255-261.

Klose, M., Juul, A., Struck, J., Morgenthaler, N. G., Kosteljanetz, M., and Feldt-Rasmussen, U. (2007a). Acute and long-term pituitary insufficiency in traumatic brain injury: a prospective single-centre study. Clin. Endocrinol. (Oxf.) 67, 598-606.

Klose, M., Watt, T., Brennum, J., and Feldt-Rasmussen, U. (2007b). Posttraumatic hypopituitarism is associated with unfavourable body composition and lipid profile, and decreased quality of life 12 months after injury. J. Clin. Endocrinol. Metab. 92, 3861-3868.

Kokshoorn, N. E., Wassenaar, M. J., Biermasz, N. R., Roelfsema, F., Smit, J. W., Romijn, J. A. and Pereira, A. M. (2010). Hypopituitarism following traumatic brain injury: prevalence is affected by the use of different dynamic tests and different normal values. Eur. J. Endocrinol. 162, 11-18.

Kornblum, R. N., and Fisher, R. S. (1969). Pituitary lesions in craniocerebral injuries. Arch. Pathol. 88, 242-248.

Kreitschmann-Andermahr, I., Poll, E. M., Reineke, A., Gilsbach, J. M., Brabant, G., Buchfelder, M., Fassbender, W., Faust, M., Kann, P. H., and Wallaschofski, H. (2008). Growth hormone deficient patients after traumatic brain injury-baseline characteristics and benefits after growth hormone replacement-an analysis of the German KIMS database. Growth Horm. IGF Res. 18 472-478.
Leal-Cerro, A., Flores, J. M., Rincon, M., Murillo, F., Pujol, M., GarciaPesquera, F., Dieguez, C., and Casanueva, F. F. (2005). Prevalence of hypopituitarism and growth hormone deficiency in adults longterm after severe traumatic brain injury. Clin. Endocrinol. (Oxf) 62, 525-532.

Lieberman, S. A., Oberoi, A. L., Gilkison, C. R., Masel, B. E., and Urban, R. J. (2001). Prevalence of neuroendocrine dysfunction in patients recovering from traumatic brain injury. J. Clin. Endocrinol. Metab. 86, 2752-2756.

Lorenzo, M., Peino, R., Castro, A. I., Lage, M., Popovic, V., Dieguez, C., and Casanueva, F. F. (2005). Hypopituitarism and growth hormone deficiency in adult subjects after traumatic brain injury: who and when to test. Pituitary 8, 233-237.

Malya, B., Newcombe, V., Nortje, J., Bradley, P., Bernard, F., Chatfield, D. Outtrim, J., Hutchinson, P., Matta, B., Antoun, N., and Menon, D. (2008). Magnetic resonance imaging changes in the pituitary gland following acute traumatic brain injury. Intensive Care Med. 34, 468-475.

Moon, R. J., Sutton, T., Wilson, P. M., Kirkham, F. J., and Davies, J. H. (2010). Pituitary function at longterm follow-up of childhood traumatic brain injury. J. Neurotrauma 27, 1827-1835.

Norwood, K. W., DeBoer, M. D., Gurka, M. J., Kuperminc, M. N., Rogol, A. D., Blackman, J. A., Wamstad, J. B., Buck, M. L., and Patrick, P. D. (2010). Traumatic brain injury in children and adolescents: surveillance for pituitary dysfunction. Clin. Pediatr. (Phila.) 49, 1044-1049.

Popovic, V., Leal, A., Micic, D., Koppeschaar, H. P., Torres, E., Paramo, C., Obradovic, S., Dieguez, C., and Casanueva, F. F. (2000) $\mathrm{GH}-$ releasing hormone and $\mathrm{GH}$ releasing peptide-6 for diagnostic testing in GH-deficient adults. Lancet 356, 1137-1142.

Popovic, V., Pekic, S., Pavlovic, D., Maric, N., Jasovic-Gasic, M., Djurovic, B., Medic Stojanoska, M., Zivkovic, V., Stojanovic, M., Doknic, M., Milic, N., Djurovic, M., Dieguez, C., and Casanueva, F. F. (2004). Hypopituitarism as a consequence of traumatic brain injury (TBI) and its possible relation with cognitive disabilities and mental distress. J. Endocrinol. Invest. 27, 1048-1054.

Ruggeri, R. M., Smedile, G., Granata, F., Longo, M., Cannaio, S., Sarlis, N. J., Trimarchi, F., and Benvega, S. (2010). Spontaneous recovery from isolated post-traumatic central 
hypogonadism in a woman. Hormones (Athens) 9, 332-337.

Salazar, A. M., Warden, D. L., Schwab, K., Spector, J., Braverman, S., Walter, J., Cole, R., Rosner, M. M., Martin, E. M., Ecklund, J., and Ellenbogen, R. G. (2000). Cognitive rehabilitation for traumatic brain injury: a randomized trial. Defense and Veterans Head Injury Program (DVHIP) Study Group. JAMA 283, 3075-2081.

Salehi, F., Kovacs, K., Scheithauer, B. W., Pfeifer, E. A., and Cusimano, M. (2007). Histologic study of the human pituitary gland in acute traumatic brain injury. Brain Inj. 21, 651-656.

Schneider, H. J., KreitschmannAndermahr, I., Ghigo, E., Stalla, G. K., and Agha, A. (2007). Hypothalamopituitary dysfunction following traumatic brain injury and aneurysmal subarachnoid hemorrhage: a systematic review. JAMA 298, 1429-1438.

Schneider, H. J., Schneider, M., Saller, B., Petersenn, S., Uhr, M., Husemann, B., von Rosen, F., and Stalla, G. K. (2006). Prevalence of anterior pituitary insufficiency 3 and 12 months after traumatic brain injury. Eur. J. Endocrinol. 154, 259-265.

Schneider, M., Schneider, H. J., Yssouridis, A., Saller, B., von Rosen, F., and Stalla, G. K. (2008). Predictors of anterior pituitary insufficiency after traumatic brain injury. Clin. Endocrinol. (Oxf.) 68, 206-212.

Tagliaferri, F., Compagnone, C., Korsic, M., Servadei, F., and Kraus, J. (2006). A systematic review of brain injury epidemiology in Europe. Acta Neurochir. (Wien) 148, 255-268.

Tanriverdi, F., De Bellis, A., Battaglia, M., Bellastella, G., Bizzarro, A., Sinisi, A. A., Bellastella, A., Unluhizarci, K., Selcuklu, A., Casanueva, F. F. and Kelestimur, F. (2010a). Investigation of antihypothalamus and antipituitary antibodies in amateur boxers: is chronic repetitive head trauma-induced pituitary dysfunction associated with autoimmunity? Eur. J. Endocrinol. 162, 861-867.

Tanriverdi, F., Unluhizarci, K., Karaca, Z., Casanueva, F. F., and Kelestimur, F. (2010b). Hypopituitarism due to sports related head trauma and the effects of growth hormone replacement in retired amateur boxers. Pituitary 13, 111-114.

Tanriverdi, F., De Bellis, A., Bizzarro, A., Sinisi, A. A., Bellastella, G., Pane, E., Bellastella, A., Unluhizarci, K., Selcuklu, A., Casanueva, F. F. and Kelestimur, F. (2008a). Antipituitary antibodies after traumatic brain injury: is head trauma-induced pituitary dysfunction associated with autoimmunity? Eur. J. Endocrinol. 159, 7-13.
Tanriverdi, F., Ulutabanca, H., Unluhizarci, K., Selcuklu, A. Casanueva, F. F., and Kelestimur, F. (2008b). Three years prospective investigation of anterior pituitary function after traumatic brain injury: a pilot study. Clin. Endocrinol. (Oxf.) 68, 573-579.

Tanriverdi, F., Unluhizarci, K., Kocyigit, I., Tuna, I. S., Karaca, Z., Durak, A C., Selcuklu, A., Casanueva, F. F., and Kelestimur, F. (2008c). Brief Communication: pituitary volume and function in competing and retired male boxers. Ann. Intern. Med. 148, 827-831.

Tanriverdi, F., Senyurek, H., Unluhizarci, K., Selcuklu, A., Casanueva, F. F., and Kelestimur F. (2006). High risk of hypopituitarism after traumatic brain injury: a prospective investigation of anterior pituitary function in the acute phase and 12 months after trauma. J. Clin. Endocrinol. Metab. 91, 2105-2111.

Teasdale, G., and Jennett, B. (1974). Assessment of coma and impaired consciousness. A practical scale. Lancet 2, 81-84.

Van den, B. G., de Zegher, F., and Bouillon, R. (1998). Clinical review 95: acute and prolonged critical illness as different neuroendocrine paradigms. J. Clin. Endocrinol. Metab. 83, 1827-1834.
Wachter, D., Gündling, K., Oertel, M. F., Stracke, H., and Böker, D. K. (2009). Pituitary insufficiency after traumatic brain injury. J. Clin. Neurosci. 16, 202-208.

Conflict of Interest Statement: The authors declare that the research was conducted in the absence of any commercial or financial relationships that could be construed as a potential conflict of interest.

Received: 02 December 2010; accepted: 09 August 2011; published online: 25 August 2011.

Citation: Fernandez-Rodriguez E, Bernabeu I, Castro AI, Kelestimur F and Casanueva FF (2011) Hypopituitarism following traumatic brain injury: determining factors for diagnosis. Front. Endocrin. 2:25. doi: 10.3389/fendo.2011.00025

This article was submitted to Frontiers in Pituitary Endocrinology, a specialty of Frontiers in Endocrinology.

Copyright (C) 2011 Fernandez-Rodriguez, Bernabeu, Castro, Kelestimur and Casanueva. This is an open-access article subject to a non-exclusive license between the authors and Frontiers Media SA, which permits use, distribution and reproduction in other forums, provided the original authors and source are credited and other Frontiers conditions are complied with. 